\title{
Neuromelanin is an immune stimulator for dendritic cells in vitro
}

\author{
Uwe Oberländer ${ }^{1}$, Katrien Pletinckx', Anja Döhler, Nora Müller ${ }^{1}$, Manfred B Lutz ${ }^{1}$, Thomas Arzberger², \\ Peter Riederer ${ }^{3}$, Manfred Gerlach ${ }^{4}$, Eleni Koutsilieri ${ }^{1}$ and Carsten Scheller ${ }^{1 *}$
}

\begin{abstract}
Background: Parkinson's disease (PD) is characterized at the cellular level by a destruction of neuromelanin (NM)containing dopaminergic cells and a profound reduction in striatal dopamine. It has been shown recently that antimelanin antibodies are increased in sera of Parkinson patients, suggesting that NM may act as an autoantigen. In this study we tested whether NM is being recognized by dendritic cells (DCs), the major cell type for inducing Tand B-cell responses in vivo. This recognition of NM by DCs is a prerequisite to trigger an adaptive autoimmune response directed against NM-associated structures.

Results: Murine DCs were treated with NM of substantia nigra (SN) from human subjects or with synthetic dopamine melanin (DAM). DCs effectively phagocytized NM and subsequently developed a mature phenotype (CD86 ${ }^{\text {high }} / \mathrm{MHCII}^{\text {high }}$ ). NM-activated DCs secreted the proinflammatory cytokines IL- 6 and TNF- $\alpha$. In addition, they potently triggered $T$ cell proliferation in a mixed lymphocyte reaction, showing that DC activation was functional to induce a primary T cell response. In contrast, DAM, which lacks the protein and lipid components of NM but mimics the dopamine-melanin backbone of $\mathrm{NM}$, had only very little effect on DC phenotype and function.

Conclusions: NM is recognized by DCs in vitro and triggers their maturation. If operative in vivo, this would allow the DC-mediated transport and presentation of SN antigens to the adaptive immune system, leading to autoimmmunity in susceptible individuals. Our data provide a rationale for an autoimmune-based pathomechanism of PD with NM as the initial trigger.
\end{abstract}

\section{Background}

Parkinson's disease (PD) is a progressive neurodegenerative disorder characterized at the cellular level by a destruction especially of neuromelanin (NM)-containing dopaminergic cells and a profound reduction in striatal dopamine. NM accumulates in the cytoplasm of dopaminergic neurons starting within the first 3-5 years after birth [1-3]. NM concentration increases with age and its optical density has been shown to increase until 60 years of life [4]. In patients with juvenile PD as well as with idiopathic and MPTP-induced PD, NM also accumulates in the extracellular space of substantia nigra (SN) [5-7].

Exracellular NM does not behave passively. Both protective and toxic effects have been reported (reviewed

\footnotetext{
* Correspondence: scheller@vim.uni-wuerzburg.de

'University of Würzburg, Institute of Virology and Immunobiology, Würzburg, Germany

Full list of author information is available at the end of the article
}

by Zecca $[8,9])$. The protective role is most notably through its ability to trap free radicals and toxins [8]. Toxic effects of NM are mainly due to NM highly-complexed with iron $[10,11]$. In vitro NM activates microglia by triggering NK- $\kappa \mathrm{B}$ activation and the release of the proinflammatory cytokines TNF- $\alpha$ and IL-6 [12]. When injected into the brains of rats, human NM triggers neuroinflammation and neurodegeneration $[13,14]$, suggesting a proinflammatory role for NM.

The primary etiological factor for PD is still unknown. Several hypotheses have been proposed [15-18]. Autoimmune processes in PD have been suggested previously $[19,20]$. Autoantibodies directed at neuronal structures have been found in sera of PD patients [21-25]. In an interesting study brains of PD patients exhibited an IgG binding on dopamine neurons, which was positively correlated with the number of HLA positive microglia [26]. Moreover, in the same study the low affinity activating IgG receptor FcrRIII was expressed on cells
Ciomed Central

(c) 2011 Oberländer et al; licensee BioMed Central Ltd. This is an Open Access article distributed under the terms of the Creative Commons Attribution License (http://creativecommons.org/licenses/by/2.0), which permits unrestricted use, distribution, and reproduction in any medium, provided the original work is properly cited. 
morphologically resembling lymphocytes. In a recent publication by Double et al., sera from subjects with clinical PD were found to display significantly enhanced IgG-levels specific for melanin derived from catecholamines, a structural component of NM [16]. Moreover, complement binding to NM in brains from PD patients supports the idea of immunologic clearance of NM in PD [7]. These data suggest the possibility of a specific autoimmune response against NM in PD patients.

Dendritic cells (DC) are professional antigen-presenting cells able to initiate primary $\mathrm{T}$-cell mediated immune responses [27]. In a so-called immature state their main function is the uptake and processing of antigens. Once they become activated (either by proinflammatory cytokines or pathogens), DCs migrate into the draining lymph nodes (LN) to present the antigen to naïve $\mathrm{T}$ - and $\mathrm{B}$-cells [27]. If $\mathrm{T}$ - or $\mathrm{B}$-cells specific for this antigen enter the $\mathrm{LN}$, the cells become primed to exert their effector functions once they re-encounter the antigen in the peripheral tissue. In contrast, microglia are tissue-resident cells that are not able to migrate into lymphoid tissues to start an adaptive immune response. They are specialized to present antigens to already activated, infiltrating $\mathrm{T}$-cells. Hence, a de novo initiation of an adaptive immune response against an immunogen within the brain requires DC activation, whereas microglia activation is in this context a downstream event in order to direct the $\mathrm{T}$ - and $\mathrm{B}$ - cell response to the site where the antigen is located. DCs are spare in the healthy CNS. However, they do accumulate in the CNS parenchyma in neuroinflammation and CNS autoimmune disease following monocyte invasion, from which they differentiate [28-33].

In this study we hypothesize that extracellular NM may stimulate DC maturation and thereby promote $\mathrm{NM}$-associated antigen presentation in an autoimmunogenic context. This would reflect the initiating step of an autoagressive activity against antigens from SN. Therefore, we investigated whether NM can be recognized and taken up by DCs and subsequently explored the capability of NM to mature/activate these cells phenotypically and functionally for $\mathrm{T}$ cell activation. Using synthetic dopamine melanin (DAM), we investigated the role of the domanine melanin "backbone" found in NM in DC activation.

\section{Results}

\section{Dendritic cells phagocytose NM and DAM}

In order to assess whether DCs recognize NM as a potential antigen we coincubated DCs with NM and studied phagocytosis by differential interference contrast microscopy. NM was visible as small black granules of 0.5-5 $\mu \mathrm{m}$ size (Figure 1). After 24 hours of co-incubation with DCs NM colocalized with DCs in the culture plate (Figure 1). A z-stack analysis revealed that NM granules were not just attached to the cell surface but were indeed internalized by DCs (Figure 1D). Similarly, DCs also phagocytosed DAM (Figure 2).

\section{DCs mature in response to NM}

Phagocytosis of NM resulted within $48 \mathrm{~h}$ in maturation of DCs measured by the upregulation of the cell surface molecules MHCII and CD86. Whereas only 13\% of the DC population displayed a mature phenotype in the absence of additives in the culture medium, the amount of mature DCs increased to $66.8 \%$ following contact with NM (Figure 3A, C and 3E; Bonferroni post hoc test, $\mathrm{p}<0.001)$. DAM triggered comparably lower DC activation (31.6\%) compared to NM (Figure 3B and 3E; $\mathrm{p}<0.001)$ but still significantly elevated compared to medium alone $(\mathrm{p}<0.01)$. As a positive control, DCs were treated with LPS (Figure 3D and 3E), a strong activator of DCs. LPS-activation in the experiments displayed in this manuscript should only be regarded qualitatively (instead of quantitatively), as the amount of LPS used in these experiments is in no relation whatsoever to the amount of NM or DAM, except for the fact that it was titrated in order to provoke a response. We therefore did not apply statistical analysis comparing the magnitude of the LPS response with other treatments.

\section{NM generates a functional activation of DCs}

Following $48 \mathrm{~h}$ exposure to NM, DCs released significantly higher amounts of proinflammatory cytokines such as TNF- $\alpha$ and IL- 6 compared to cells treated with medium alone ( $\mathrm{p}<0.01$ and $<0.001$, respectively), demonstrating that NM-triggered DC maturation generated functional cells (Figure 4A, B). No additional cytokine release compared to cells treated with mediumalone was detected in cells treated with DAM.

In order to test whether NM-stimulated DCs can activate $\mathrm{T}$ cell proliferation (a necessary event in the translation of a $\mathrm{DC}$ signal into a $\mathrm{T}$ cell response), we performed a mixed lymphocyte reaction (MLR) in which $T$ cells isolated from allogenic donor mice were cocultured with NM- or DAM-treated DCs. As depicted in Figure 4C, NM-treated DCs were able to trigger a proliferative $\mathrm{T}$ cell response $(\mathrm{p}<0.001$ compared to untreated cells). In contrast to the effects triggered by $\mathrm{NM}$, no T cell proliferation could be detected following incubation with DAM.

The experiments displayed in Figure 4 not only demonstrate that NM-triggered DC activation generates completely functional DCs (cells that are able to migrate to the lymph nodes and present antigens to $\mathrm{T}$ cells and that also have the capacity to trigger proliferative $\mathrm{T}$ cell responses), but also narrows the number of NM-compounds that could actually be the trigger of it: As 

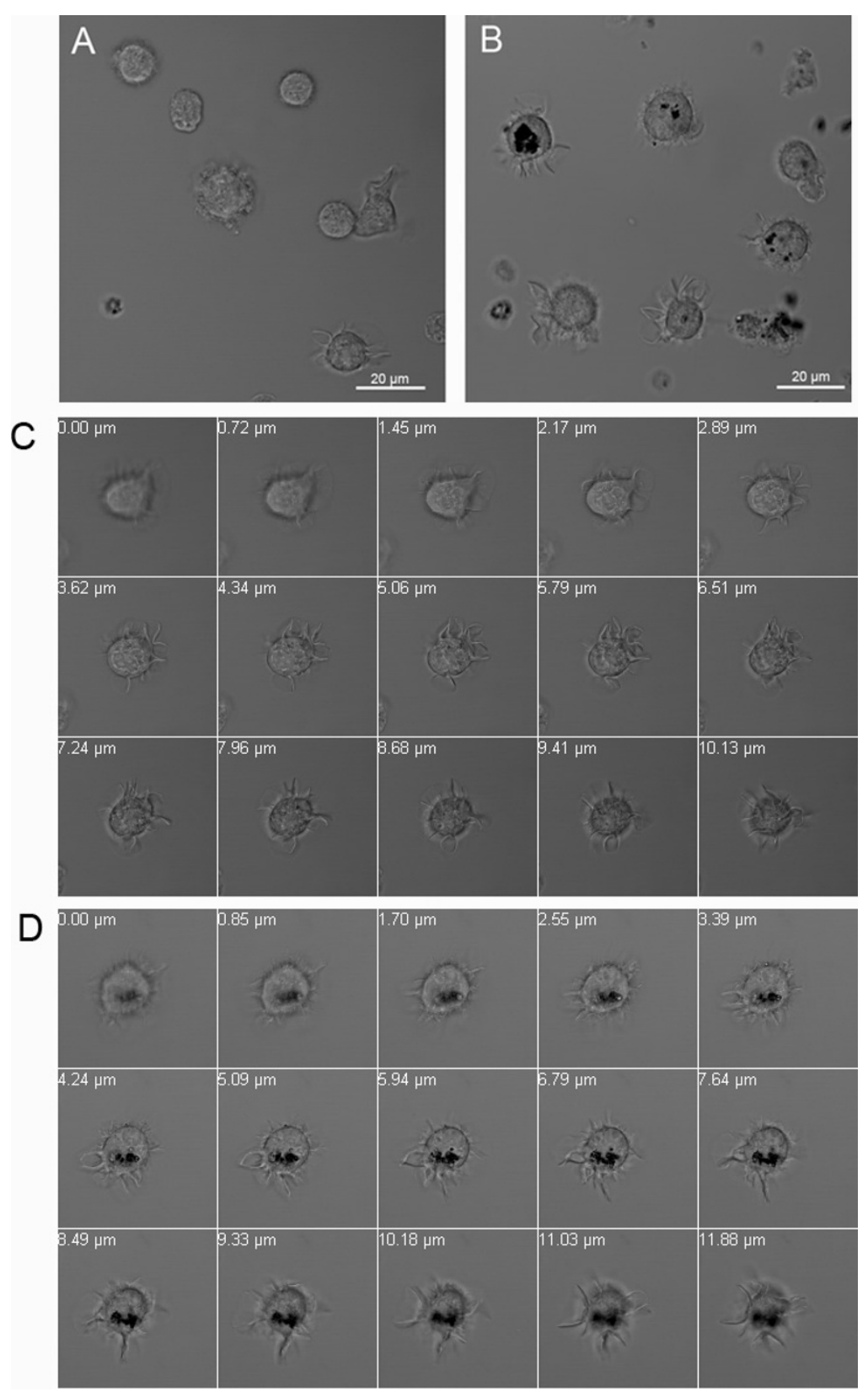

Figure 1 Dendritic cells (DC) phagocytose neuromelanin (NM). Cells were cultured for $48 \mathrm{~h}$ in the absence (A, C) or presence (B, D) of neuromelanin (NM) and analyzed by differential interference contrast (DIC) microscopy. A, B: Overview of cultures. C, D: z-stack analysis of a single DC from bottom to top. Z-stack distances were 0.70-0.80 $\mu \mathrm{m}$.

synthetic DAM, which lacks many of the compounds found in NM (lipids, proteins) failed to triggered any cytokine or proliferative response at all, the dopamine melanine itself is probably not the stimulus for these events. However, the dopamine melanine "backbone" of NM could play an important role in efficient uptake of NM by DCs, as we observed that DAM alone is being recognized and phagocytosed very efficiently by DCs (Figure 2).

\section{NM preparations are free of endotoxin contamination}

DCs are very sensitive towards LPS (which for this reason was used as a positive control in the experiments depicted above). In order to exclude a potential endotoxin contamination of the DAM and NM preparations used in our experiments, we tested the DAM- and NMsuspensions for LPS using a commercially available LAL assay. No traces of LPS were detected in the DAM- and NM-suspensions used for our experiments (Figure 5). 

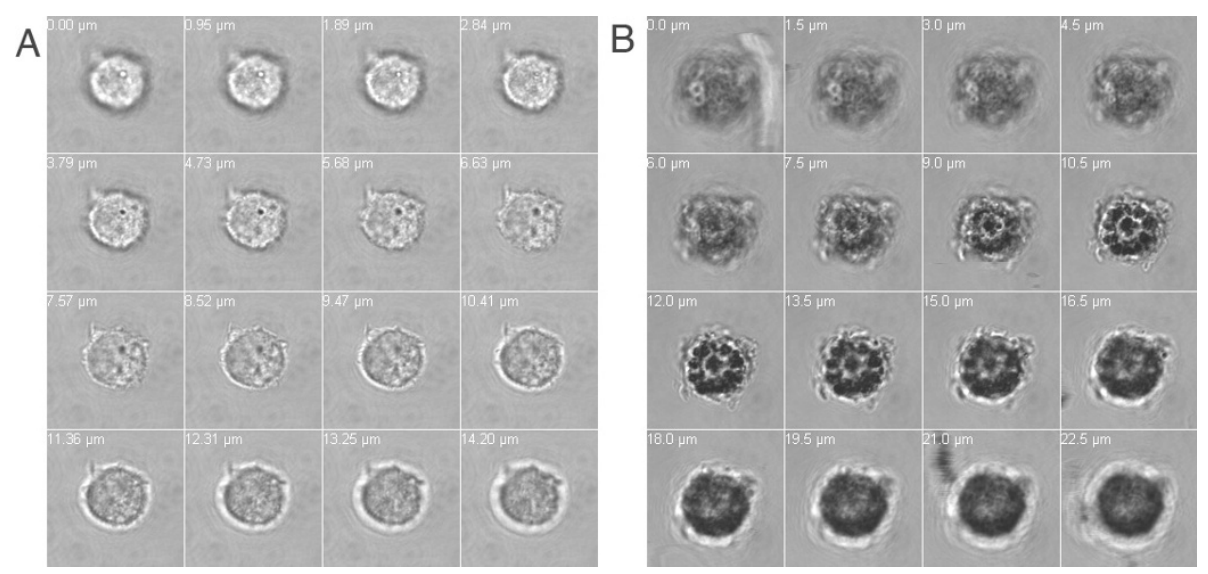

Figure 2 Dendritic cells (DC) phagocytose synthetic dopamine melanin (DAM). Cells were cultured for $48 \mathrm{~h}$ in the absence (A) or presence (B) of DAM. Differential interference contrast (DIC) microscopy with z-stack analysis of DCs from bottom to top. Z-stack distances were $1.5 \mu \mathrm{m}$.

These results suggest that the DC-stimulating effects are intrinsic for NM and were not caused by a potential contamination with endotoxin.

\section{Discussion}

Our in vitro study shows that a) extracellular NM is being phagocytosed by DCs and b) NM triggers maturation and functional activation of these cells. If operative in vivo, this would inevitably cause a transport of extracellular NM from the brain into cervical lymph nodes, resulting in a presentation of NM to naïve $\mathrm{T}$ - and $\mathrm{B}$ cells in a highly immunogenic context. This may eventually lead to the development of an autoimmune disease directed at NM-associated antigens. Our study therefore offers a first evidence for a NM-driven autoimmune-based pathogenesis of PD with NM as the initial trigger of a DC-mediated autoantigen presentation.

Although an autoimmune-based pathogenesis of PD that targets NM has yet to be conclusively demonstrated in vivo, a number of previous findings can now be put into a broader perspective: Sera from subjects with clinical PD display enhanced IgG-levels to catecholeaminebased melanins, the structural basis of the NM present in the pigmented neurons of the human SN [16], indicating an immune response directed against $\mathrm{NM}$ itself. In line with this, opsonization of NM with $\mathrm{Clq}$ - a complement factor involved in the classical complement pathway that recognizes antigen-bound IgG and IgM has been shown on the surface of extracellular NM in post-mortem brains of $\mathrm{PD}$-patients [7]. Alternatively (or additionally), DC-phagocytosis of NM loaded with resident peptides or proteins (the high affinity of NM to peptides has been shown before [34]) may initiate the presentation of formerly-unrecognized autoantigens to $\mathrm{T}$ - and B-cells in a "Trojan Horse way", triggering an adaptive autoimmune response directed at proteins primarily unrelated to NM. In this regard Orr et al. found in post-mortem sections from PD patients - but not from age-matched controls - IgG antibodies directed at pigmented dopamine neurons and auto-IgG binding colocalized with immunostaining for Lewy bodies [26].

Mature DCs loaded with autoantigens have been shown to be able to induce autoimmunity against the loaded antigen in mice [35]. Although DCs seem to be rare in the healthy brain, myeloid-derived DCs infiltrate the brain during neuroinflammation [28-33] so that DCs are likely to encounter extracellular NM also in vivo.

Our data indicate that the DC-activating properties of $\mathrm{NM}$ are conferred by its peptide or lipid components (but not by the dopamine melanine backbone). Although the primary repertoire of endogenous lipids and peptides is unlikely to be able to activate DCs, oxidative modifications of endogenous molecules are being discussed to confer DC-maturating activity by an "altered-self" mechanism [36]. Such DC-maturating activity has already been described for oxidized lipophosphatidylcholine (LPC) found in low-density lipoprotein (LDL), which potently triggers DC maturation and activation $[37,38]$. In a similar way, oxidized protein or lipid contents of NM could have triggered DC maturation in our assay system. In line with this, post-mortem studies with brains from PD patients revealed increased lipidperoxidation in SN [10,39].

Our findings that NM activates DCs are in line with previous reports that $\mathrm{NM}$ can activate microglia both in vitro [14] and in vivo when injected into the rat brain $[13,14]$. Microglia and DCs are both myeloid antigen presenting cells that are closely related, albeit they fulfill completely different but also cooperative functions during an immune response. Whereas activated DCs will leave the tissue and transport the antigen to the lymph nodes in order to initiate an adaptive immune response, 

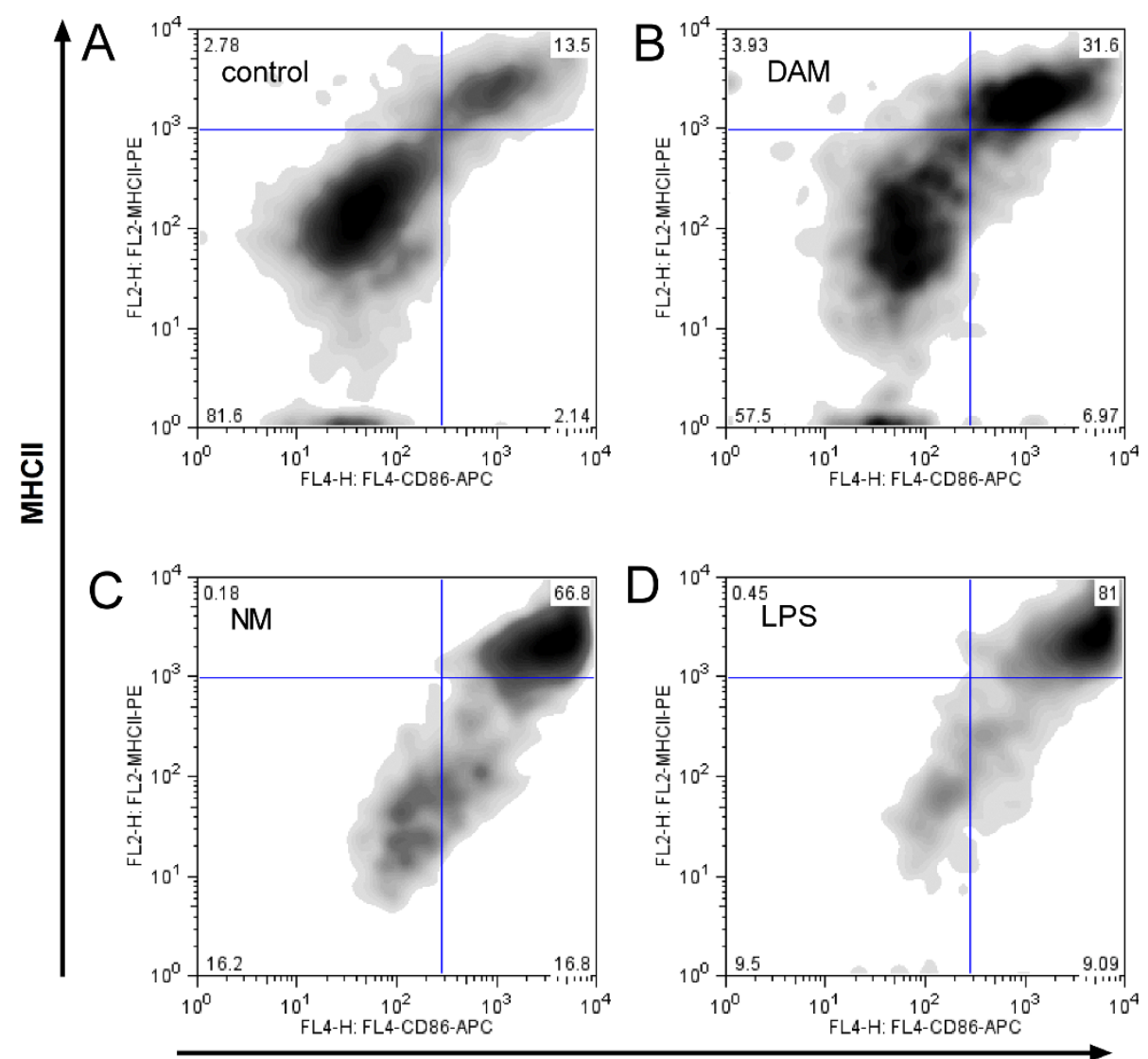

CD86

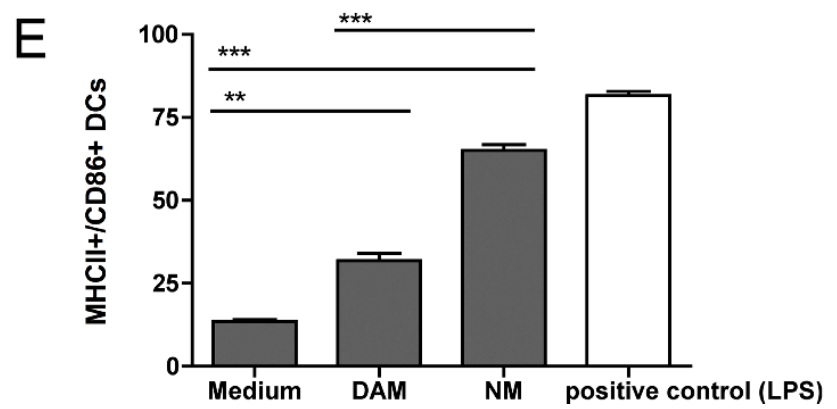

Figure 3 Neuromelanin triggers dendritic cell (DC) maturation. Flow cytometric analysis of DC maturation by staining with anti-CD86/antiMHCIl antibodies. A: medium-treated DCs (untreated). B: DAM-treated DCs. C: NM-treated DCs. D: positive control (LPS-treated DCs). A-D: representative experiments from triplicates. E: Illustration of the amount of mature DCs from triplicates (data as mean \pm S.E.M.; statistical analysis with one-way ANOVA using Bonferroni multiple comparison as post test; n.s. $=$ non specific $\left.(p>0.05),{ }^{*} p<0.05,{ }^{* *} p<0.01,{ }^{* * *} p<0.001\right)$.

activated microglia reside in the tissue and present the antigen to DC-primed infiltrating $\mathrm{T}$ cells in order to direct the immune response to the tissue in which the antigen was found. Therefore, combining the results of the former study on microglia with our results opens a new autoimmune scenario: NM not only causes local inflammation (activation of microglia) but may also trigger an adaptive immune response directed at NM itself via activation of DCs. Our findings therefore add a potential third characteristic to NM in relation to PD: whereas NM has previously been discussed to be either neuroprotective or neurotoxic (and the inflammatory activity of NM on microglia would be a neurotoxic characteristic in the broadest sense) our findings suggest that it might also be considered as an initial trigger for an adaptive autoimmune response. 


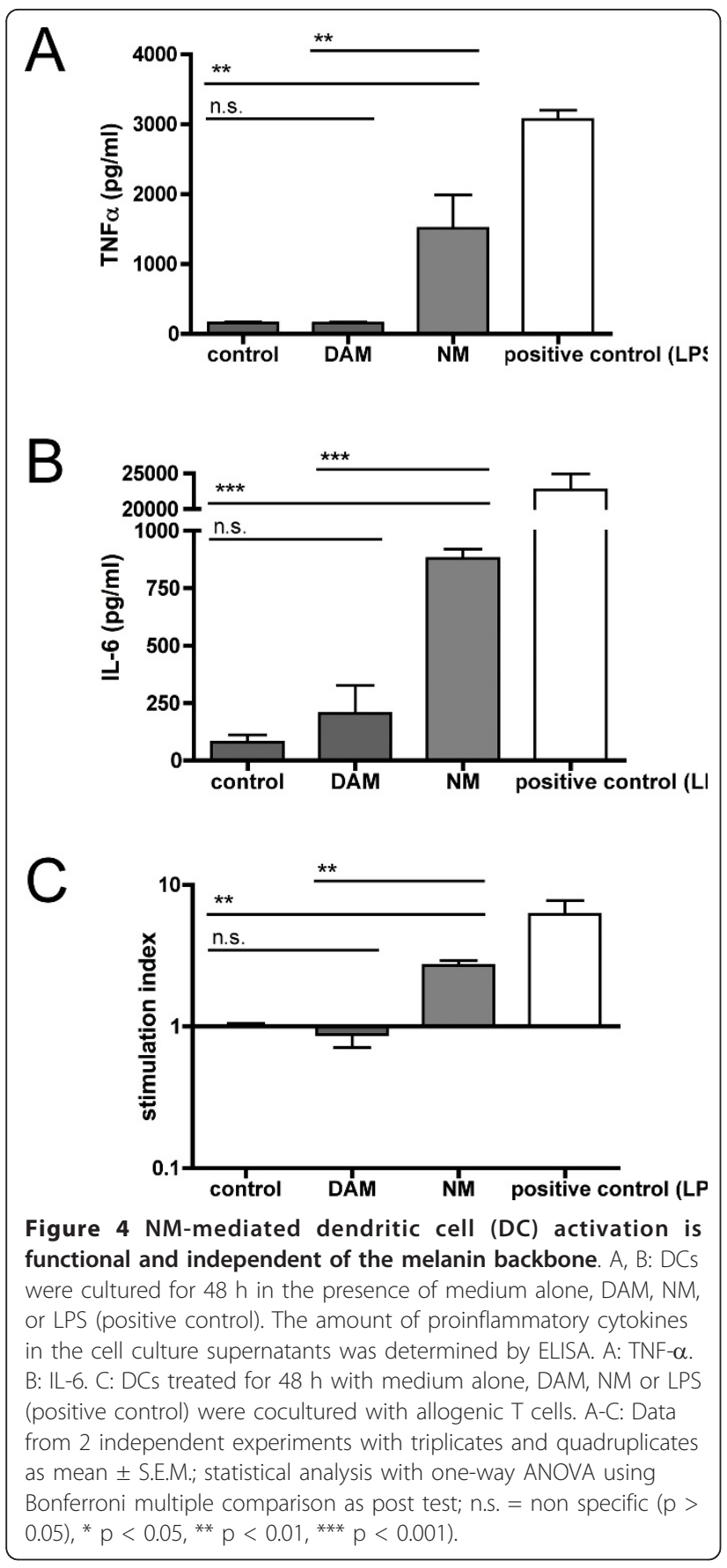

\section{Conclusions}

Our data suggest that extracellular NM may be the initial trigger for an adaptive autoimmune response relevant for PD via activation of DCs. Whatever the antigen (s) recognized in an autoimmune etiology of PD may be, our data now offers an explanation for the initial trigger of the autoimmune response against $\mathrm{SN}$-antigens, i.e. the activation of DCs by a substance exclusively found in the affected areas, the NM.

\section{Methods}

\section{NM preparation}

Human SN tissue was obtained from the "AustrianGerman-Brain-Bank" in Würzburg. The use of post mortem human brain tissue was approved by the Ethics Committee of the University Clinics of Würzburg. The SN was dissected from post mortem brains of subjects with no history of neurological, neurodegenerative or psychiatric diseases within $36 \mathrm{~h}$ of death on a cool plate $\left(-15^{\circ} \mathrm{C}\right)$. Only cases with a macroscopically regular pigmentation of the $\mathrm{SN}$ and a post mortem delay of less than $36 \mathrm{~h}$ were selected for preparation. The SN was dissected from transversally cut midbrain slices on a cool plate $\left(-15^{\circ} \mathrm{C}\right)$. NM was isolated according the method previously published [40]. The prepared NM was resuspended in PBS at a concentration of $5 \mathrm{mg} / \mathrm{ml}$ by pipetting.

\section{Dopamine melanin (DAM) synthesis}

Synthetic dopamine melanin (DAM), a widely used model of human NM (see for example, [41]) was produced by incubation for 2 weeks of $1 \mathrm{mM}$ dopamine hydrochloride with $0.1 \mathrm{mM}$ cupric sulfate pentahydrate in phosphate buffered saline ( $\mathrm{pH}$ 7.4). The resulting solid oxidation product was then washed in distilled water and centrifuged four times before being lyophilized. DAM was sonicated in phosphate-buffered saline to produce a suspension of fine, homogenous granules at a concentration of $1 \mathrm{mg} / \mathrm{ml}$. All chemicals were obtained from Sigma-Aldrich, Germany.

\section{Confocal Microscopy}

Cells were seeded onto $\mu$-slide VI (ibidi, Germany). Images were obtained using a Zeiss 510 Meta confocal Microscope (Zeiss, Germany) with a $63 \times$ objective (NA1.4). Z-stack analysis was performed with imaging software SP3.2 (Zeiss, Germany).

\section{Animals}

C57BL/6 (Charles River/Wiga, Sulzfeld, Germany) and $\mathrm{BALB} / \mathrm{c}$ mice (house bred) were kept under SPF (specificpathogen free conditions) in our facilities. 4-12 weeks old female mice were sacrificed by cervical dislocation in order to isolate bone marrow and lymph nodes, respectively.

\section{Bone marrow and lymph node isolation}

Femurs and tibiae from C57BL/6 mice were removed and purified from the surrounding muscle tissue by rubbing with Kleenex tissues. Thereafter intact bones were left in 70\% ethanol for 2-5 min for desinfection and washed with PBS. Then both ends were cut with scissors and the marrow was flushed out with PBS using a syringe with 0.45 $\mathrm{mm}$ diameter needle. Cell clusters were dissociated by vigorous pipetting and cells were washed with PBS. 1-1.5 $\times$ $10^{7}$ leukocytes were obtained per femur or tibia. 


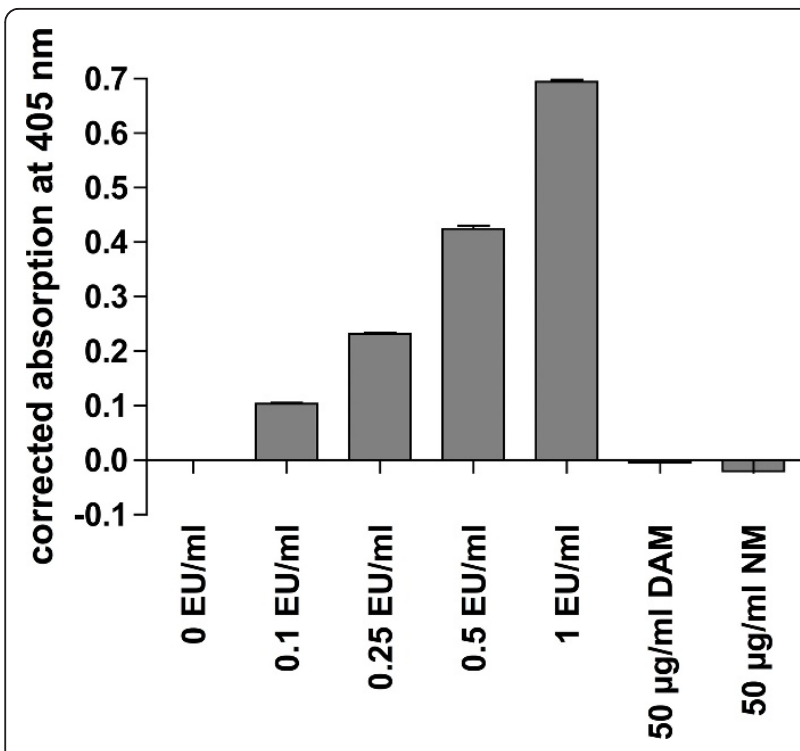

Figure 5 Negative test of LPS contamination. The DAM- and NM-preparations used in this study were tested with an endpoint chromogenic LAL-assay for LPS contamination at a concentration of $50 \mu \mathrm{g} / \mathrm{ml}$ and analyzed at a wavelength of $405 \mathrm{~nm}$. LPS standards with a concentration range between 0.1-1.0 EU/ml were tested positive, whereas the DAM and NM-preparations were tested negative for LPS.

Lymph nodes from BALB/c-mice were removed and a single cell suspension was prepared by grinding the lymph nodes between the rough ends of two sterile slides. The lymphocytes were filtered through a $70 \mu \mathrm{m}$ Falcon Cell Strain (BD Biosciences, Germany).

\section{Generation of bone-marrow DCs}

DCs were generated from bone marrow of mice as described previously with some modifications [42]. Briefly, bone marrow cells were cultured in $100 \mathrm{~mm}$ bacteriological petri dishes (Greiner bio-one, Germany) with R10 (RPMI-1640 supplemented with $10 \%$ heatinactivated fetal calf serum, penicillin $(100 \mathrm{U} / \mathrm{ml})$, streptomycin $(100 \mu \mathrm{g} / \mathrm{ml})$, L-glutamin $(2 \mathrm{mM})$, and 2-mecraptoethanol $(50 \mu \mathrm{M}$, Sigma-Aldrich, Germany)). All media components were obtained from PAA, Germany.

At day 0 bone marrow cells were seeded at $3 \times 10^{6}$ cells per dish in $10 \mathrm{ml} \mathrm{R} 10$ medium containing $10 \%$ GM-CSF supernatant from a cell line transfected with the murine GM-CSF gene [43]. At day 3 and 6 another $10 \mathrm{ml} \mathrm{R} 10$ medium containing 10\% GM-CSF supernatant was added to the plates. At day 8 cells were used for experiments.

\section{Treatment of DCs with NM, DAM and LPS}

If not indicated otherwise, DCs were treated for $48 \mathrm{~h}$ with NM, DAM at a final concentration of $50 \mu \mathrm{g} / \mathrm{ml}$ or lipopolysaccharide (LPS) at $1 \mu \mathrm{g} / \mathrm{ml}$ (Sigma-Aldrich,
Germany) or left untreated in a 24 well plate with $10^{6}$ cells/well. NM- and DAM suspensions used in DC stimulation experiments were checked for endotoxin contamination and found negative (cutoff was $0.1 \mathrm{EU} / \mathrm{ml}$; endpoint chromogenic Limulus Amebocyte Lysate (LAL) assay, Lonza, Germany).

\section{Flow cytometry}

DCs were characterized by flow cytometry. $1 \times 10^{5}$ cells were stained with fluorochrome-conjugated antibodies directed at CD86 (coupled to APC) and MHCII (coupled to PE) (both BD Biosciences, Germany) at pretitrated concentrations at $4^{\circ} \mathrm{C}$ for 60 minutes. Cells were fixed with $2 \%$ formalin and analyzed using a FACSCalibur (BD Biosciences, Germany). Cell debris was excluded from analysis by FSC-SSC gating. Quadrants were set according to staining patterns with isotype-control antibodies (all antibodies from BD Biosciences, Germany). Flow cytometry data was analyzed using FlowJo software (Tree Star Inc., OR, USA).

\section{ELISA}

Tumor necrosis factor (TNF)- $\alpha$ and interleukin (IL)-6 concentrations were determined from supernatans of NM- or LPS-treated or untreated DCs using the respective OptEIA Kits (BD Biosciences, Germany) according to the instructions of the manufacturer.

\section{Allogeneic mixed lymphocyte reaction (MLR)}

DCs from C57BL/6 mice were treated with NM, LPS or left untreated for $48 \mathrm{~h}$. At day 3, DCs were coincubated with lymphocytes isolated from BALB/c lymph nodes in triplicate cultures (96 well) at $3 \times 10^{5}$ cells/well and a ratio of $1: 1$. At day 3 , cells were pulsed with $1 \mu \mathrm{Ci} /$ well $\left[{ }^{3} \mathrm{H}\right]$ methyl-thymidine (Amersham Biosciences, Switzerland) over night for $16 \mathrm{~h}$. The plates were harvested onto glassfiber filtermats with an Tomtec harvester and filters counted in a 1450 Microplate Counter (Wallac, Turku, Finland).

\section{Test of endotoxin contamination}

The NM-preparation used for the experiments depicted in this manuscript was tested for potential contamination with endotoxin using a chromogenic Limulus amebocytes lysate (LAL) assay according to the instructions of the manufacturer (Lonza, Germany). Briefly, 50 $\mu$ l of NM sample $(100 \mu \mathrm{g} / \mathrm{ml})$, LPS standards $(0.1-1.0 \mathrm{EU} / \mathrm{ml})$ or endotoxin-free water were mixed with $100 \mu \mathrm{l}$ of LAL and incubated for $10 \mathrm{~min}$ at $37^{\circ} \mathrm{C}$. Substrate solution was added and samples were incubated for an additional $6 \mathrm{~min}$ at $37^{\circ} \mathrm{C}$. Enzyme reaction was stopped with diluted sulfuric acid and chromogen absorption was measured in a plate photometer at a wavelength of 405 $\mathrm{nm}$. To account for NM-intrinsic absorption at $405 \mathrm{~nm}$, 
a turbidity control with $100 \mu \mathrm{g} / \mathrm{ml} \mathrm{NM}$ without LAL (volume compensated with water) was measured and the value was subtracted from NM-sample absorption at $405 \mathrm{~nm}$.

\section{Statistical analysis}

Statistical analysis was performed using GraphPad Prism software for Macintosh (version $4.0 \mathrm{c}$ ). Data are expressed as mean \pm S.E.M.. For comparison of values between different treatment groups, one-way ANOVA was used together with Bonferroni multiple comparison as post test; $\mathrm{p}>0.05$ was regarded as non specific, $\mathrm{p}<$ 0.05 was attributed with *, $\mathrm{p}<0.01$ was attributed with $* *$, and $\mathrm{p}<0.001$ was attributed with $* * *$.

\section{List of abbreviations}

Parkinson's disease (PD), neuromelanin (NM), dendritic cells (DCs), dopamine melanin (DAM), substantia nigra (SN), interleukin-6 (IL-6), tumor necrosis factor (TNF), major histocompatibility complex (MHC), differential interference contrast (DIC)

\section{Acknowledgements and Funding}

The study was supported by grants from the "Verein zur Durchführung Neurowissenschaftlicher Tagungen e.V" and the DFG through an SFB581 project for $\mathrm{AD}$ and $\mathrm{MBL}$. We thank Thomas Elpel for the preparation of NM and DAM. Publication costs were covered by the Deutsche Forschungsgemeinschaft http://www.dfg.de and the University of Würzburg http://www.uni-wuerzburg.de by the funding programme "Open Access Publishing." The funders had no role in study design, data collection and analysis, decision to publish, or preparation of the manuscript.

\section{Author details}

'University of Würzburg, Institute of Virology and Immunobiology, Würzburg, Germany. ${ }^{2}$ University of Munich, Institute of Neuropathology, Munich, Germany. ${ }^{3}$ University of Würzburg, Clinical Neurochemistry (National Parkinson Foundation Center of Excellence Research Laboratory), Clinic and Policlinic of Psychiatry, Psychosomatics and Psychotherapy, Würzburg, Germany. ${ }^{4}$ University of Würzburg, Laboratory of Clinical Neurobiology, Department of Child and Adolescent Psychiatry, Psychosomatics and Psychotherapy, Würzburg, Germany.

\section{Authors' contributions}

UO carried out treatment of DCs with NM, DAM and LPS and performed immunological charactertization of the response of DCs to NM including the MLR. KP and AD carried out bone marrow and lymph node isolation and generation of bone-marrow DCs. NM performed confocal microscopy. MBL participated in study design, supervized DC preparation and helped to draft the manuscript. TA, PR and MG participated in coordination and design of the study and helped to draft the manuscript. EK and CS conceived of the study, participated in all steps of the work and drafted the manuscript. All authors read and approved the final manuscript.

Received: 14 September 2011 Accepted: 15 November 2011 Published: 15 November 2011

\section{References}

1. Zecca L, Gallorini M, Schunemann V, Trautwein AX, Gerlach M, Riederer P, Vezzoni P, Tampellini D: Iron, neuromelanin and ferritin content in the substantia nigra of normal subjects at different ages: consequences for iron storage and neurodegenerative processes. J Neurochem 2001, 76(6):1766-1773

2. Fenichel GM, Bazelon M: Studies on neuromelanin. II. Melanin in the brainstems of infants and children. Neurology 1968, 18(8):817-820.

3. Fedorow $H$, Tribl F, Halliday G, Gerlach M, Riederer P, Double KL: Neuromelanin in human dopamine neurons: comparison with peripheral melanins and relevance to Parkinson's disease. Prog Neurobiol 2005, 75(2):109-124.

4. Mann DM, Yates PO: Lipoprotein pigments-their relationship to ageing in the human nervous system. II. The melanin content of pigmented nerve cells. Brain 1974, 97(3):489-498.

5. Ishikawa A, Takahashi H: Clinical and neuropathological aspects of autosomal recessive juvenile parkinsonism. J Neurol 1998, 245(11 Suppl 3):P4-9.

6. Langston JW, Forno LS, Tetrud J, Reeves AG, Kaplan JA, Karluk D: Evidence of active nerve cell degeneration in the substantia nigra of humans years after 1-methyl-4-phenyl-1,2,3,6-tetrahydropyridine exposure. Ann Neurol 1999, 46(4):598-605.

7. Depboylu C, Schafer MK, Arias-Carrion O, Oertel WH, Weihe E, Hoglinger GU: Possible involvement of complement factor c1q in the clearance of extracellular neuromelanin from the substantia nigra in Parkinson disease. J Neuropathol Exp Neurol 2011, 70(2):125-132.

8. Zecca L, Zucca FA, Wilms H, Sulzer D: Neuromelanin of the substantia nigra: a neuronal black hole with protective and toxic characteristics. Trends Neurosci 2003, 26(11):578-580.

9. Rao KS, Hegde ML, Anitha S, Musicco M, Zucca FA, Turro NJ, Zecca L: Amyloid beta and neuromelanin-toxic or protective molecules? The cellular context makes the difference. Prog Neurobiol 2006, 78(6):364-373.

10. Ben-Shachar D, Riederer P, Youdim MB: Iron-melanin interaction and lipid peroxidation: implications for Parkinson's disease. J Neurochem 1991, 57(5):1609-1614.

11. Double KL, Halliday GM, Henderson J, Griffiths FM, Heinemann T, Riederer P, Gerlach M: The dopamine receptor agonist lisuride attenuates ironmediated dopaminergic neurodegeneration. Exp Neurol 2003, 184(1):530-535.

12. Wilms H, Rosenstiel P, Sievers J, Deuschl G, Zecca L, Lucius R: Activation of microglia by human neuromelanin is NF-kappaB dependent and involves p38 mitogen-activated protein kinase: implications for Parkinson's disease. FASEB J 2003, 17(3):500-502.

13. Zecca L, Wilms H, Geick S, Claasen JH, Brandenburg LO, Holzknecht C, Panizza ML, Zucca FA, Deuschl G, Sievers J, Lucius R: Human neuromelanin induces neuroinflammation and neurodegeneration in the rat substantia nigra: implications for Parkinson's disease. Acta Neuropathol 2008, 116(1):47-55

14. Zhang W, Phillips K, Wielgus AR, Liu J, Albertini A, Zucca FA, Faust R, Qian SY, Miller DS, Chignell CF, Wilson B, Jackson-Lewis V, Przedborski S, Joset D, Loike J, Hong JS, Sulzer D, Zecca L: Neuromelanin activates microglia and induces degeneration of dopaminergic neurons: implications for progression of Parkinson's disease. Neurotox Res 2011, 19(1):63-72.

15. Gerlach M, Double KL, Youdim MB, Riederer P: Potential sources of increased iron in the substantia nigra of parkinsonian patients. J Neural Transm Supp/ 2006, 70:133-142.

16. Double KL, Rowe DB, Carew-Jones FM, Hayes M, Chan DK, Blackie J, Corbett A, Joffe R, Fung VS, Morris J, Riederer P, Gerlach M, Halliday GM: Anti-melanin antibodies are increased in sera in Parkinson's disease. Exp Neurol 2009, 217(2):297-301.

17. Wood-Kaczmar A, Gandhi S, Wood NW: Understanding the molecular causes of Parkinson's disease. Trends Mol Med 2006, 12(11):521-528.

18. Riederer P, Foley P: Mini-review: multiple developmental forms of parkinsonism. The basis for further research as to the pathogenesis of parkinsonism. J Neural Transm 2002, 109(12):1469-1475.

19. Benkler M, Agmon-Levin N, Shoenfeld Y: Parkinson's disease, autoimmunity, and olfaction. Int J Neurosci 2009, 119(12):2133-2143.

20. Moscavitch SD, Szyper-Kravitz M, Shoenfeld Y: Autoimmune pathology accounts for common manifestations in a wide range of neuropsychiatric disorders: the olfactory and immune system interrelationship. Clin Immunol 2009, 130(3):235-243.

21. Papachroni KK, Ninkina N, Papapanagiotou A, Hadjigeorgiou GM, Xiromerisiou G, Papadimitriou A, Kalofoutis A, Buchman VL: Autoantibodies to alpha-synuclein in inherited Parkinson's disease. J Neurochem 2007, 101(3):749-756.

22. Roselli F, Russo I, Fraddosio A, Aniello MS, De Mari M, Lamberti P, Livrea P, Defazio G: Reversible Parkinsonian syndrome associated with antineuronal antibodies in acute EBV encephalitis: a case report. Parkinsonism Relat Disord 2006, 12(4):257-260. 
23. Hassin-Baer S, Levy Y, Langevitz P, Nakar S, Ehrenfeld M: Anti-beta2glycoprotein I in Sjogren's syndrome is associated with parkinsonism. Clin Rheumatol 2007, 26(5):743-747.

24. Wilhelm KR, Yanamandra K, Gruden MA, Zamotin V, Malisauskas M, Casaite V, Darinskas A, Forsgren L, Morozova-Roche LA: Immune reactivity towards insulin, its amyloid and protein S100B in blood sera of Parkinson's disease patients. Eur J Neurol 2007, 14(3):327-334.

25. Dale RC, Church AJ, Surtees RA, Lees AJ, Adcock JE, Harding B, Neville BG, Giovannoni G: Encephalitis lethargica syndrome: 20 new cases and evidence of basal ganglia autoimmunity. Brain 2004, 127(Pt 1):21-33

26. Orr CF, Rowe DB, Mizuno Y, Mori H, Halliday GM: A possible role for humoral immunity in the pathogenesis of Parkinson's disease. Brain 2005, 128(Pt 11):2665-2674.

27. Banchereau J, Steinman RM: Dendritic cells and the control of immunity. Nature 1998, 392(6673):245-252.

28. McMenamin PG: Distribution and phenotype of dendritic cells and resident tissue macrophages in the dura mater, leptomeninges, and choroid plexus of the rat brain as demonstrated in wholemount preparations. J Comp Neurol 1999, 405(4):553-562.

29. Bailey TW, Hermes SM, Andresen MC, Aicher SA: Cranial visceral afferent pathways through the nucleus of the solitary tract to caudal ventrolateral medulla or paraventricular hypothalamus: target-specific synaptic reliability and convergence patterns. J Neurosci 2006, 26(46):11893-11902.

30. Zozulya AL, Ortler S, Lee J, Weidenfeller C, Sandor M, Wiendl H, Fabry Z Intracerebral dendritic cells critically modulate encephalitogenic versus regulatory immune responses in the CNS. J Neurosci 2009, 29(1):140-152

31. Fischer HG, Reichmann G: Brain dendritic cells and macrophages/ microglia in central nervous system inflammation. J Immunol 2001, 166(4):2717-2726.

32. Santambrogio L, Belyanskaya SL, Fischer FR, Cipriani B, Brosnan CF, RicciardiCastagnoli P, Stern L, Strominger JL, Riese R: Developmental plasticity of CNS microglia. Proc Natl Acad Sci USA 2001, 98(11):6295-6300.

33. Bailey SL, Schreiner B, McMahon EJ, Miller SD: CNS myeloid DCs presenting endogenous myelin peptides 'preferentially' polarize CD4+ $\mathrm{T}(\mathrm{H})-17$ cells in relapsing EAE. Nat Immunol 2007, 8(2):172-180.

34. Zecca L, Costi P, Mecacci C, Ito S, Terreni M, Sonnino S: Interaction of human substantia nigra neuromelanin with lipids and peptides. $J$ Neurochem 2000, 74(4):1758-1765.

35. Eriksson U, Ricci R, Hunziker L, Kurrer MO, Oudit GY, Watts $T H$, Sonderegger I, Bachmaier K, Kopf M, Penninger JM: Dendritic cell-induced autoimmune heart failure requires cooperation between adaptive and innate immunity. Nat Med 2003, 9(12):1484-1490.

36. Atassi MZ, Casali P: Molecular mechanisms of autoimmunity. Autoimmunity 2008, 41(2):123-132.

37. Coutant F, Perrin-Cocon L, Agaugue S, Delair T, Andre P, Lotteau V: Mature dendritic cell generation promoted by lysophosphatidylcholine. J Immunol 2002, 169(4):1688-1695.

38. Perrin-Cocon L, Coutant F, Agaugue S, Deforges $S$, Andre P, Lotteau V: Oxidized low-density lipoprotein promotes mature dendritic cell transition from differentiating monocyte. J Immunol 2001, 167(7):3785-3791.

39. Shamoto-Nagai M, Maruyama W, Hashizume Y, Yoshida M, Osawa T, Riederer P, Naoi M: In parkinsonian substantia nigra, alpha-synuclein is modified by acrolein, a lipid-peroxidation product, and accumulates in the dopamine neurons with inhibition of proteasome activity. J Neural Transm 2007, 114(12):1559-1567.

40. Li J, Scheller C, Koutsilieri E, Griffiths F, Beart PM, Mercer LD, Halliday G, Kettle E, Rowe D, Riederer P, Gerlach M, Rodriguez M, Double KL: Differential effects of human neuromelanin and synthetic dopamine melanin on neuronal and glial cells. J Neurochem 2005, 95(2):599-608.

41. Ostergren A, Svensson AL, Lindquist NG, Brittebo EB: Dopamine melaninloaded PC12 cells: a model for studies on pigmented neurons. Pigment Cell Res 2005, 18(4):306-314.

42. Lutz MB, Kukutsch N, Ogilvie AL, Rossner S, Koch F, Romani N, Schuler G: An advanced culture method for generating large quantities of highly pure dendritic cells from mouse bone marrow. J Immunol Methods 1999, 223(1):77-92.

43. Zal T, Volkmann A, Stockinger B: Mechanisms of tolerance induction in major histocompatibility complex class II-restricted T cells specific for a blood-borne self-antigen. J Exp Med 1994, 180(6):2089-2099. doi:10.1186/1471-2202-12-116

Cite this article as: Oberländer et al: Neuromelanin is an immune stimulator for dendritic cells in vitro. BMC Neuroscience 2011 12:116.

\section{Submit your next manuscript to BioMed Central and take full advantage of:}

- Convenient online submission

- Thorough peer review

- No space constraints or color figure charges

- Immediate publication on acceptance

- Inclusion in PubMed, CAS, Scopus and Google Scholar

- Research which is freely available for redistribution 